\title{
Innovative Practices in Optimal Utilization of Solar Energy (Solar Tracking System)
}

\author{
Dr. G. Suresh Babu \\ EEE Dept., C.B.I.T
}

\begin{abstract}
As the demand is ahead of the supply there is a dire need for efficient and effective utilization of resources. Hence an attempt is made to reduce the utilization of electricity from fossil fuel by optimally utilizing the Solar Energy. Which is achieved by Solar Tracking System. As the Solar Energy is one of the substitutes for fossil fuel, a breakthrough is achieved by adopting an alternative technique which is christened as Solar Tracking System A solar tracker is a device that orients a payload toward the sun. Payloads can be photovoltaic panels, reflectors, lenses or other optical devices. In flat-panel photovoltaic (PV) applications, trackers are used to minimize the angle of incidence between the incoming sunlight and a photovoltaic panel. This increases the amount of energy produced from a fixed amount of installed power generating capacity and reduces the quantity of number of Solar Panels.
\end{abstract}

Keywords: Solar Tracking System, Flat-Panel Photovoltaic (PV), LDR, Solar Panels, Solar Energy.

\section{INTRODUCTION}

Renewable Energy is rapidly gaining importance as an energy resource since the fossil fuels are depleting. At the Educational level, owing to difficulties in simulation process, the design and development of renewable energy modules has not grown considerable in the academia.

One of the most popular renewable energy sources is Solar Energy. Much research has been done to develop certain methods to increase the efficiency of Photo Voltaic systems (solar panels) [1]. One such method is to employ a Solar Panel Tracking System. This paper deals with a Microcontroller based solar panel tracking system. Solar tracking enables more energy to be generated because the solar panel is always able to maintain a perpendicular profile to the sun's rays [2]. Development of solar panel tracking systems has been ongoing for several years now. As the sun moves across the sky during the day, it is advantageous to have the solar panels track the location of the sun, such that the panels are always perpendicular to the solar energy radiated by the sun. This will tend to maximize the amount of power absorbed by PV systems. It has been estimated that the use of a tracking system, over a fixed system, can increase the power output by $30 \%$ - 60\% [3]. The increase is significant enough to make tracking a viable preposition despite of the enhancement in system cost. It is possible to align the tracking heliostat normal to sun using electronic control by a micro controller. Design requirements are:

a) The Heliostat should move in order to maintain the orthognality with the sun rays every instant.

b) This must be done with an active control and timed movements are useful. It should be totally automatic and simple to operate. The operator interference should be minimal and restricted to only when it is actually required

\section{TRACKING PRINCIPLE}

Many different methods have been proposed and used to track the position of the sun. The simplest of all uses an LDR a Light Dependent Resistor to detect light intensity changes on the surface of the resistor. The resistivity of
LDR decreases significantly with increasing illumination. The efficiency of LDR increases with directed rays. Fig. 1 shows the general resistivity vs. illumination plot of an LDR.

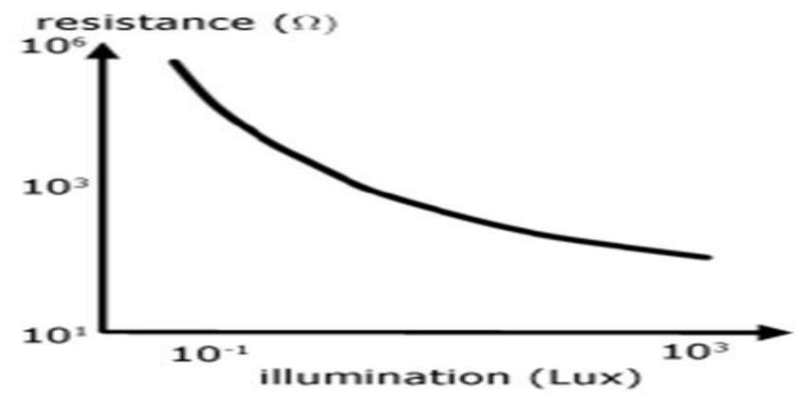

Fig. 1 Resistivity vs. illumination plot of an LDR

\section{BLOCK DIAGRAM REPRESENTATION}

The description of the each block in Fig. 3 is given below.

\subsection{Power supply}

This device needs $+5 \mathrm{~V} / 500 \mathrm{~mA}$ DC power supply for the micro controller section and $+12 \mathrm{~V}$ DC/1A power supply for the motors.

\subsection{Controlling section: Microcontroller}

The Microcontroller is the main controlling part of the whole system. It controls the whole tracking by following certain algorithm.

\subsection{Input section: LDR sensor}

This is the main input section where the analog level of volt-age is collected by the microcontroller's Analog to Digital converter (ADC) for further processing.

\subsection{Output section: Motor driver}

Motor driver circuit is used for driving the D.C motors. There are two separate drivers for driving two separate D.C motors.

\subsection{Motor unit}

There are two motor units. One for movement of base (horizontal movement) and other for vertical movement. 


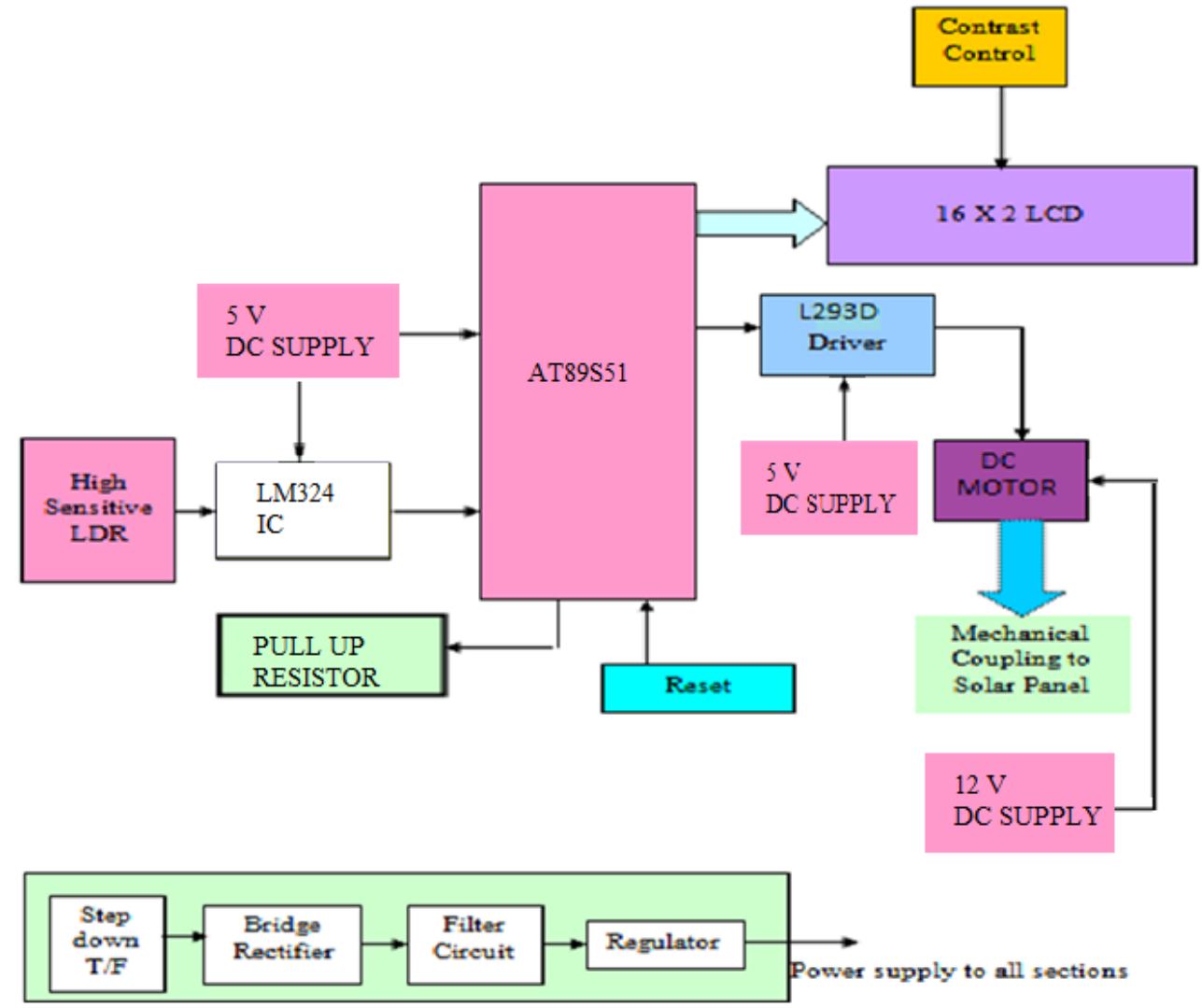

Fig. 2 Block Diagram of Solar Tracking System

\subsection{Indication}

These are simple Light Emitting Diodes (LEDs). The red LED indicates the power supply. The yellow LED glows when total calculation is being carried on by the MCU. When calculation is over, the system stabilizes in the direction of the Sun and the green LED glows.

\section{STRUCTURAL DESCRIPTION OF THE DEVICE}

There are two D.C motors used for movement of Solar Panel (horizontal and vertical). The vertical motor is responsible for movement of the upper base and the horizontal motor is used for movement of the stand or base (Lower). Four photo sensors (LDR) are placed around the solar panel. From the light sensor a feedback signal is sent to the microcontroller for defining how much the motors should rotate according to an algorithm.

The microcontroller also gives feedback signal to all connected solar devices to align towards the sun. In the connected solar devices there is an arrangement similar to the tracking system except the controller section. Only two motors are installed in the solar devices for movement in horizontal and vertical direction respectively. Detailed description is as follows:

\subsection{Power supply}

The AC mains (220-250V) voltage is stepped down by the center tap transformer (15-0-15), rectified by bridge rectifier and finally filtered out by capacitors to obtain a steady DC level. Then it is passed to a +5 volt DC regulator (IC7805) and +12 volt DC regulator (IC7812) to obtain a +12 volt DC output.

\subsection{Microcontroller}

The Microcontroller we have used here is ATMEGA16 which belongs to ATMEL AVR microcontroller family. Detailed programming is written here. The ATmega16 is a 40pin low-power CMOS 8-bit microcontroller based on the AVR enhanced RISC architecture.

The Atmega16 has three key features that satisfy our objective. These are as follows: 512 Bytes EEPROM, 32 Programmable I/O Lines, inbuilt 10 bit 8 channel Analogto-Digital converter. The block diagram of AT89S51 is shown in figure 3.

\subsection{LDR sensor module}

This is the light sensor which senses the intensity of sunlight. The sun tracker system designed here uses the Cadmium Sulphide (CdS) photocell for sensing the light. This photocell is a passive component whose resistance is inversely proportional to the amount of light intensity directed towards it. It is connected in series with resistor.

\subsection{D.C Motor Drivers (L293D)}

L293D is a dual H-bridge motor driver integrated circuit (IC) [6]. Motor drivers act as current amplifiers since they take a low-current control signal and provide a highercurrent signal. This higher current signal is used to drive the motors.

L293D contains two inbuilt H-bridge driver circuits. In its common mode of operation, two DC motors can be driven simultaneously, both in forward and reverse direction. The motor operations of two motors can be controlled by input logic at pins $2 \& 7$ and $10 \& 15$. 
INTERNATIONAL JOURNAL OF INNOVATIVE RESEARCH IN ELECTRICAL, ELECTRONICS, INSTRUMENTATION AND CONTROL ENGINEERING Vol. 3, Issue 12, December 2015

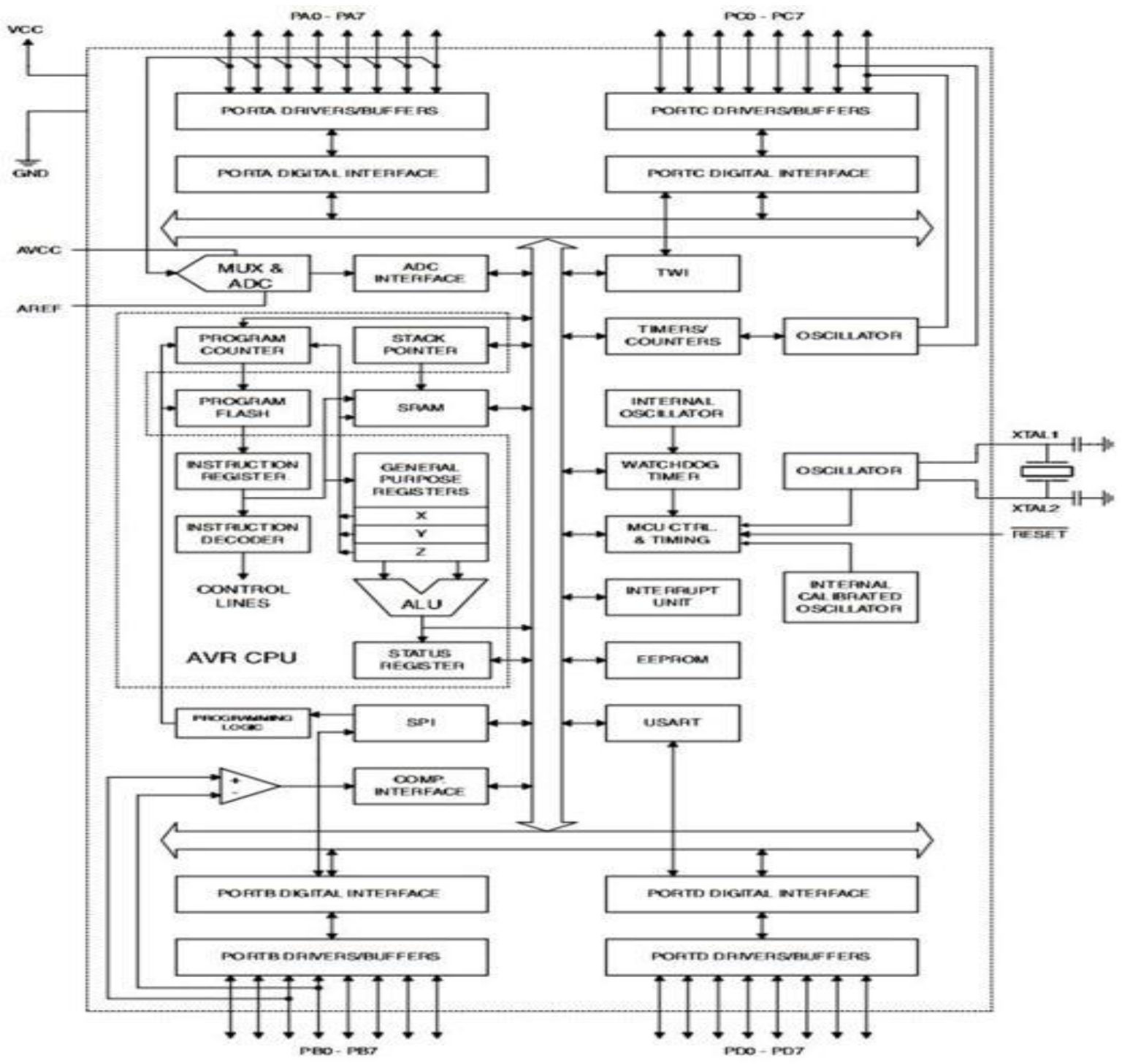

Fig. 3 Block Diagram of AT89S51

Input logic 00 or 11 will stop the corresponding motor. maximize the efficiency of solar panel systems is sun Logic 01 and 10 will rotate it in clockwise and tracking. A solar panel receives the most sunlight when it anticlockwise directions, respectively.

\subsection{LDR Driver (LM324)}

LM324 is a 14pin IC consisting of four independent Operational Amplifiers (Op-Amps) compensated in a single package [6]. Op-amps are high gain electronic voltage amplifier with differential input and, usually, a single-ended output. The output voltage is many times higher than the voltage difference between input terminals of an op-amp.

These op-amps are operated by a single power supply LM324 and need for a dual supply is eliminated. They can be used as amplifiers, comparators, oscillators, rectifiers etc. The conventional op-amp applications can be more easily implemented with LM324.

\section{WORKING PROCEDURE}

To make solar energy more viable, efficiency of solar panel systems must be maximized. A feasible approach to

is perpendicular to the sun rays.

So, by moving a solar panel along with the direction of sunlight maximum amount of solar energy can be trapped. It uses a geared motor to change the position of the solar panel. The motor is controlled by the AT89S51 microcontroller (8051 family), which detects the sunlight using Light Dependent Resistor.

The motor and LDR are connected to the microcontroller through the driving IC's i.e. the Motor Driver LM293D and LDR Driver LM324N respectively. The objective is to design and implement an automated, two-axis solartracking mechanism using embedded system design with minimum cost and reliable structure.

It uses the Proteus Design Software for the purpose of simulation and Keil software to convert the embedded $\mathrm{C}$ language code to .hex format which is understood by the microcontroller 
INTERNATIONAL JOURNAL OF INNOVATIVE RESEARCH IN ELECTRICAL, ELECTRONICS, INSTRUMENTATION AND CONTROL ENGINEERING Vol. 3, Issue 12, December 2015

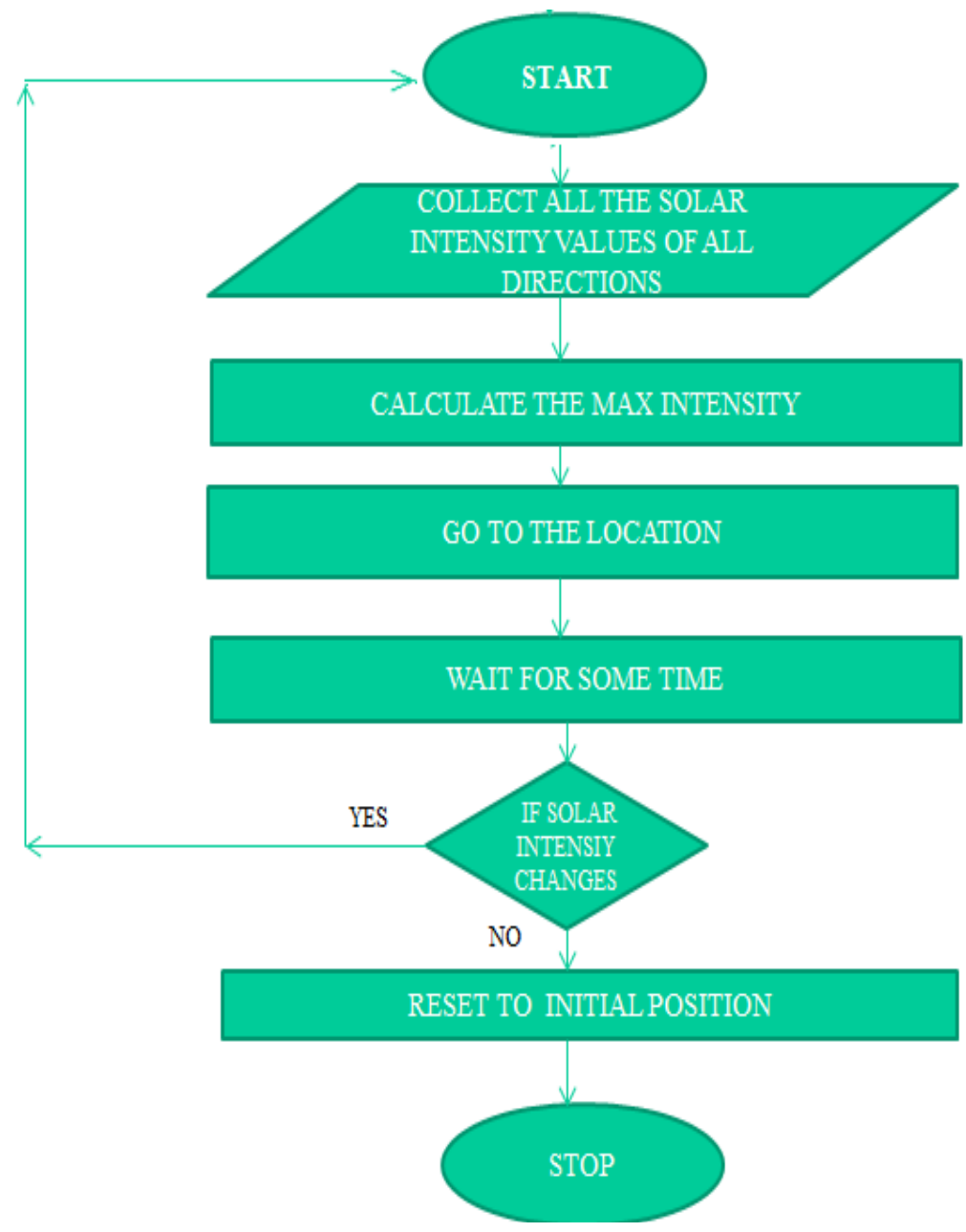

Fig 4 Flow Chart of Solar Tracking System

\section{HARD WARE (SOLAR TRACKING SYSTEM) AND RESULTS}

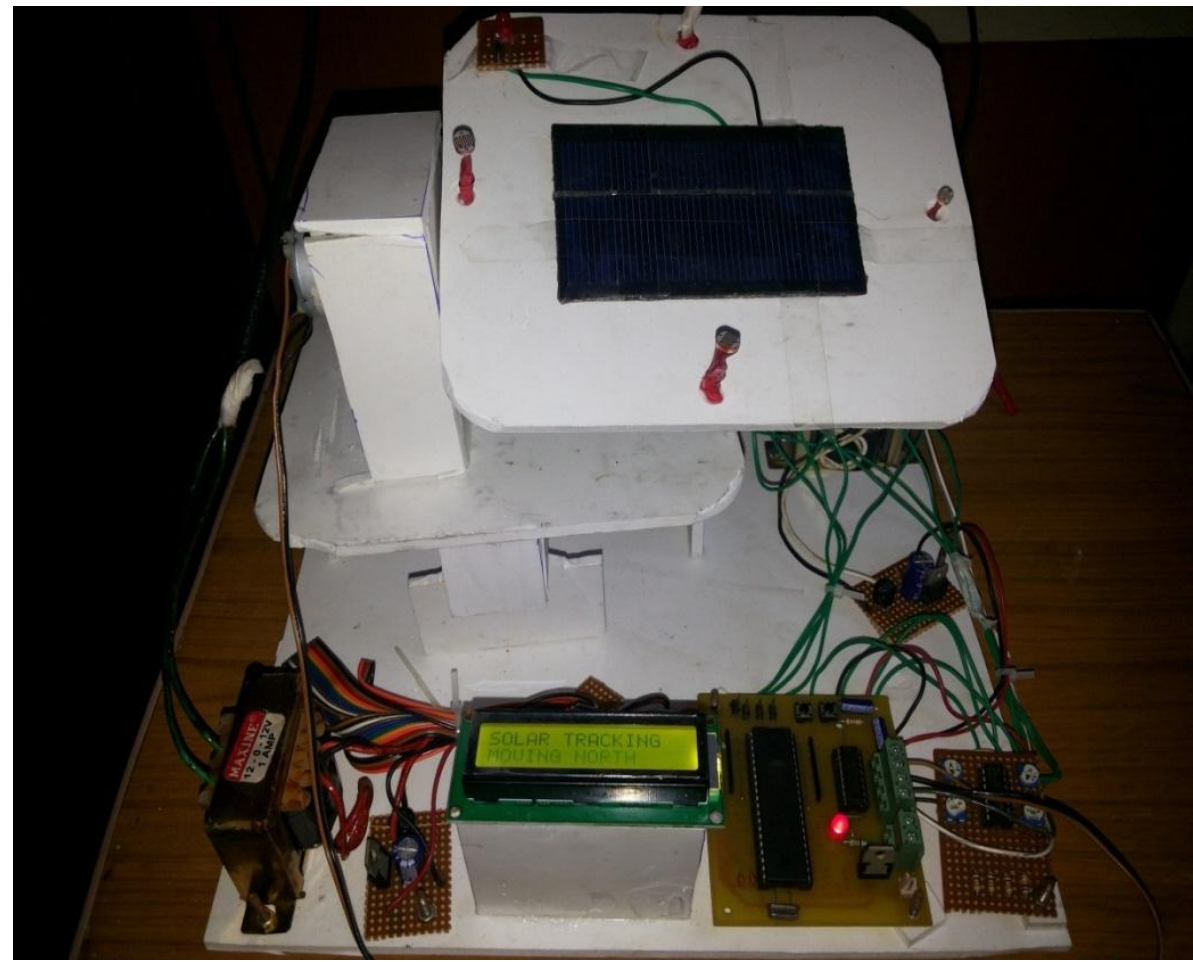

Fig 5 Hard Ware of Solar Tracking System 
These data was recorded on July-15, 2015. Table.1 represents the fixed system recorded database and Table.2 represents the recorded database for tracking system.

\begin{tabular}{|c|c|c|c|}
\hline Hour & Voltage $(\mathrm{V})$ & Current $(\mathrm{A})$ & Power $(\mathrm{W})$ \\
\hline 11.00 & 1.04 & 1.26 & 1.279 \\
\hline 11.30 & 1.10 & 1.30 & 1.430 \\
\hline $12.00 \mathrm{NOON}$ & 1.12 & 1.40 & 1.568 \\
\hline 12.30 & 1.17 & 1.45 & 1.696 \\
\hline 13.00 & 1.16 & 1.45 & 1.682 \\
\hline 13.30 & 1.08 & 1.28 & 1.382 \\
\hline 14.00 & 1.04 & 1.22 & 1.268 \\
\hline 14.30 & 1.01 & 1.17 & 1.181 \\
\hline \multicolumn{3}{|c|}{ Total Output Power $=11.504$ Watts } \\
\hline
\end{tabular}

Table 1 Fixed System

\begin{tabular}{|c|c|c|c|}
\hline Hour & Voltage $(\mathrm{V})$ & Current $(\mathrm{A})$ & Power $(\mathrm{W})$ \\
\hline 11.00 & 1.10 & 1.31 & 1.441 \\
\hline 11.30 & 1.15 & 1.41 & 1.610 \\
\hline $12.00 \mathrm{NOON}$ & 1.22 & 1.48 & 1.805 \\
\hline 12.30 & 1.3 & 1.53 & 1.989 \\
\hline 13.00 & 1.2 & 1.5 & 1.800 \\
\hline 13.30 & 1.16 & 1.39 & 1.612 \\
\hline 14.00 & 1.11 & 1.42 & 1.570 \\
\hline 14.30 & 1.10 & 1.38 & 1.518 \\
\hline \multicolumn{3}{|c|}{ Total Output Power $=13.345$ Watts } \\
\hline
\end{tabular}

Table 2 Tracking System

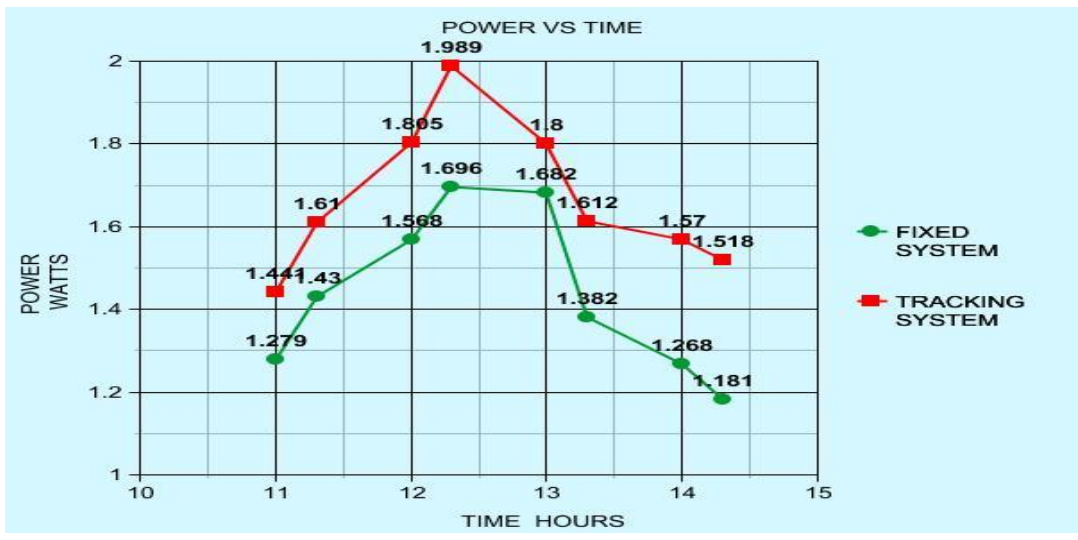

Fig 6 Plot of Tracking System

\section{CONCLUSION}

An automated Solar Tracking System has been designed and developed. Although there is higher initial cost involved, it has been tried to make the system cost effective. The solar panels using this system compared with the system prevalent at present has some advantage like the operator interference is minimal since the system is automated and this increases efficiency of the stationary solar system. The total power from the Solar tracking system is $\mathbf{1 3 . 3 4 5}$ Watts whereas that from the fixed system is $\mathbf{1 1 . 5 0 4}$ Watts. Here it can be concluded that with the help of tracking system we can extract $\mathbf{1 . 8 4 1}$ watts more power than a fixed system .From above calculated data, dual axis tracking system increases the efficiency of the system by $\mathbf{1 6 . 0 0 3 \%}$.

\section{REFERENCES}

[1] Arindam Bose, Sounak Sarkar, Sayan Das, Helianthus -a Low Cost High Efficient Solar Tracking System Using AVR
Microcontroller, International Journal of Scientific \& Engineering Research, Volume 3, Issue 10, October-2012

2] S. Krachong, J. Natwichai, L. Inchaiwong, S. Wattanasirichaigoon, S. Noimanee, High Efficiency Solar Tracking Systemfor cardiac care unit, The 3rd International Symposium on Biomedical Engineering, 2008

[3] Neeraj Tiwari, D. Bhagwan Das, Prabal Pratap Singh, Design, Development and Hardware Realization of X-BEE based single axis solar tracking system, International Journal of Electrical Engineering and Technology (IJEET), issn 0976 - 6545(print), issn 0976 - 6553(online) volume 3, issue 3, October - December 2012

[4] Barney L. Capehart, Wayne C. Turner, Guide to Energy Management

[5] Mazidi, The 8051 Microcontroller and Embedded Systems Using Assembly

[6] Julio Sanchez, Maria P. Canton, Embedded Systems: Circuits and Programming

[7] N.V. Philips' Gloeilampenfabrieken, Voltage Dependent Resistors, Light Dependent Resistors, Negative Temperature Coefficient Thermistors, Positive Temperature Coefficient Thermistors. 